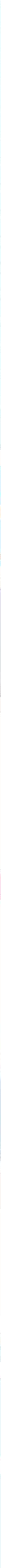




\title{
A INSERÇÃO DO ENSINO DE ARQUITETURA E URBANISMO NA PRÁTICA SOCIAL
}

\section{THE INSERTION OF ARCHITECTURE AND URBANISM TEACHING IN SOCIAL PRACTICE}

\section{LA INSERCIÓN DE LA ENSEÑANZA DE ARQUITECTURA Y URBANISMO EN LA PRÁCTICA SOCIAL}

\author{
Mônica Manso Villela* \\ Lucília Regina de Souza Machado**
}

\footnotetext{
* Professora do Curso de Engenharia na Faculdade Pitágoras. Arquiteta e Mestre em Gestão Social, Educação e Desenvolvimento Local pelo Centro Universitário UNA. Belo Horizonte, Minas Gerais, Brasil. E-mail: monicamansovillela@ gmail.com

** Coordenadora do Programa de Pós-Graduação em Gestão Social, Educação e Desenvolvimento Local do Centro Universitário UNA. Socióloga, Mestre e Doutora em Educação, Pós-Doutora em Sociologia do Trabalho. Belo Horizonte, Minas Gerais, Brasil. E-mail: Ismachado@uai.com.br

Recebido para publicação em: 22.9.2016

Aprovado em: 7.4.2017
}

\section{Resumo}

Este artigo retoma dissertações e teses sobre a formação de arquitetos urbanistas, para a discussão, análise e proposições sobre a formação desses profissionais na perspectiva da pedagogia comprometida socialmente. Localiza, na história da extensão universitária, suas práticas desenvolvidas na Faculdade Pitágoras de Arquitetura e Urbanismo. Sete categorias de análise orientaram esta pesquisa e suas conclusões focam o estreitamento das relações da educação/escola com o contexto social, a ampliação das ações das instituições para além de seus muros, a exploração de recursos pedagógicos e a aplicação do princípio educativo do trabalho.

Palavras-chave: Extensão e prática pedagógica. Formação profissional. Emau. Trabalho como princípio educativo.

\section{Abstract}

This article takes up dissertations and theses on the formal education of town planning architects aiming the discussion, analysis, and propositions about the education of such professionals in the perspective of a socially committed pedagogy. In the history of the university extension, it sets the development of its practices in the Pitágoras Architecture and Urbanism College. Seven categories of analysis guided this research and findings focus on the narrowing of the education/school relationship with the social context, the expansion of institutions' actions beyond their walls, the exploitation of pedagogical resources and the application of the work educational principle. 
Keywords: Extension and the pedagogical practice. Craft Training. Emau. Work as an educational principle.

\section{Resumen}

Este artículo retoma disertaciones y tesis sobre la formación de arquitectos urbanistas, para la discusión, análisis y proposiciones sobre la formación de estos profesionales en la perspectiva de la pedagogía comprometida socialmente. Ubica, en la historia de la extensión universitaria, sus prácticas desarrolladas en la Facultad Pitágoras de Arquitectura y Urbanismo. Siete categorías de análisis han orientado esta investigación y sus conclusiones enfocan el estrechamiento de las relaciones de la educación/escuela con el contexto social, la ampliación de las acciones de las instituciones más allá de sus muros, la explotación de recursos pedagógicos y la aplicación del principio educativo laboral.

Palabras clave: Extensión y práctica pedagógica. Formación profesional. Emau. Trabajo como principio educativo.

\section{Introdução}

Este artigo resulta de pesquisa em cinco dissertações de mestrado (BASTOS, 2007; CARSALADE, 1997; LIMA NETO, 2007; SCHREGA, 2005; VALENTE, 2004) e cinco teses de doutorado (ARCIPRESTE, 2012; DOBRY, 2008; NARUTO, 2006; PAVESI, 2007; VIDIGAL, 2010) sobre formação de arquitetos e se destinou a retomar elementos para a discussão sobre essa formação sob o ângulo da contextualização pedagógica comprometida socialmente.

A pesquisa se baseou nas concepções da Pedagogia Histórico-Crítica de Saviani (2011) como referência teórica, que propõem a prática social como ponto de partida para o trabalho do professor e de seus alunos, mas considera que tal práxis deve ser problematizada considerando-se duas questões que precisam ser resolvidas nesse âmbito: que instrumentos teóricos e práticos sejam utilizados para o equacionamento dos problemas ali identificados, e que para a transformação social e a síntese desse processo de aprendizagem elevem a compreensão de alunos e professores sobre a realidade.

Foram selecionadas sete categorias de análise para realização desse estudo: a importância do estreitamento da relação entre educação/escola e o contexto social; desencontros entre o que os estudantes estudam e as necessidades sociais; dificuldades em ampliar a escola para além de seus muros; extensão universitária como prática pedagógica; recursos pedagógicos no ensino da Arquitetura e Urbanismo; aplicação do princípio educativo do trabalho no ensino da Arquitetura e Urbanismo e estratégias para fazer a 
inserção do ensino de Arquitetura e Urbanismo na prática social. A síntese das contribuições dos autores em relação a cada uma dessas categorias será apresentada a seguir.

\section{A importância do estreitamento da relação entre educação/escola com o contexto social}

Duas subcategorias foram empregadas para sistematizar o que os autores mencionaram com relação a esta questão: o processo de aprendizagem e a experiência profissional.

Carsalade (1997), na sua dissertação sobre a formação de arquitetos, discutiu a questão da aprendizagem, considerando ser papel da educação promover no estudante um crescimento mental, tornando-o exclusivo em um meio social determinado.

Pavesi (2007) incorpora na sua discussão sobre aprendizagem essa ideia de mudança cognitiva, mas ressalta também a importância de associar a aprendizagem com mudanças sociais e afetivas amplas, envolvendo diferentes sujeitos e instâncias. Segundo esse autor, "a noção de aprendizagem é o processo capaz de operar mudanças cognitivas, sociais e afetivas importantes tanto nos indivíduos e grupos quanto nas instituições" (PAVESI, 2007, p. 64). Assim, cabe à escola formar pessoas capazes de, a partir de um problema inicial, superar obstáculos.

Essa diversidade de possíveis problemas que pede a atuação do arquiteto por si só já consiste em um desafio para a formação do profissional. Suas atribuições são muito amplas, conforme define o art. $2^{\mathrm{o}}$ da Lei n. 12.378 , de 2010, que regulamenta o exercício da Arquitetura e Urbanismo no Brasil:

I - supervisão, coordenação, gestão e orientação técnica; || - coleta de dados, estudo, planejamento, projeto e especificação; III - estudo de viabilidade técnica e ambiental; IV - assistência técnica, assessoria e consultoria; $\mathrm{V}$ - direção de obras e de serviço técnico; $\mathrm{VI}$ - vistoria, perícia, avaliação, monitoramento, laudo, parecer técnico, auditoria e arbitragem; VII - desempenho de cargo e função técnica; VIII - treinamento, ensino, pesquisa e extensão universitária; IX - desenvolvimento, análise, experimentação, ensaio, padronização, mensuração e controle de qualidade; $X$ - elaboração de orçamento; XI - produção e divulgação técnica especializada; e XII - execução, fiscalização e condução de obra, instalação e serviço técnico (BRASIL, 2010). 
É o que explica Valente (2004), quando se refere à amplitude dos contextos sociais para os quais é preciso formar os profissionais, pois eles precisam estar aptos a compreender e traduzir as necessidades não somente de indivíduos, mas também de grupos sociais e de comunidades. Tal atendimento contempla, segundo ele, a concepção, organização e construção tanto do espaço exterior quanto do interior. Acrescenta, ainda, como contextos que fazem parte deste campo de atuação profissional:

o urbanismo, a edificação, o paisagismo, a proteção do ambiente natural, a utilização dos espaços disponíveis, bem como a elaboração e execução de projetos de conservação, restauração, revitalização e reabilitação de patrimônio histórico edificado (VALENTE, 2004, p. 1).

Portanto, a necessidade do estreitamento da relação entre educação/escola e esses diferentes contextos de atuação profissional é um grande desafio para os projetos pedagógicos e currículos destinados à formação do arquiteto. $\mathrm{O}$ universo das demandas técnicas e sociais é extenso. $\mathrm{O}$ aluno ou futuro profissional, em face de demandas de diferentes origens e graus de complexidade, precisa contar com uma formação ampla e generalista.

A outra subcategoria encontrada na literatura examinada referente à importância do estreitamento entre educação/escola e o contexto social na formação de arquitetos urbanistas se refere à experiência profissional. Segundo Campos (2000, p. 153):

As experiências são definidas como marcas e registros passados que contextualizados no espaço e no tempo de sua produção se associam a saberes experienciais, diferentes dos saberes científicos. [...] A experiência de trabalho ou experiência profissional, fundada no patrimônio experiencial do trabalho passado, combina-se aos elementos originais do trabalho presente possibilitando um trabalho criativo e profissional que é capaz de produzir novas respostas a situações imprevisíveis. No processo de aquisição das novas experiências, as vivências passadas não são substituídas pelas atuais, mas, ao contrário, combinam-se entre si de forma original para enriquecer e diversificar o elenco das ações possíveis. Podemos dizer que o núcleo que estrutura o desenvolvimento profissional é constituído pelas experiências profissionais.

O graduando, no seu processo formativo escolar, nem sempre tem a possibilidade de desenvolver sua experiência profissional de modo concreto e situado. Por outro lado, as escolas precisam contar com um aparato adequado à supervisão dos estágios de seus alunos e isso nem sempre é concretizado. Com isso, os graduandos acabam tendo poucas oportunidades para desenvolver experiências de trabalho em situações reais durante a graduação. Saem, assim, do curso superior, sem nenhuma ou com uma incipiente experiência profissional e com pouca iniciativa e capacidade para tomada de decisão, mesmo que de baixa complexidade. Além disso, 
adverte Schrega (2005), para fins de aprendizado e desenvolvimento do conhecimento é importante que o exercício da experiência profissional seja ativamente percebido e desenvolvido pelo indivíduo. O autor explica que:

A experiência é, primariamente, uma ação ativo-passiva; não é primariamente cognitiva. Mas a medida do valor de uma experiência reside na percepção das relações ou continuidades a que nos conduz. Podemos e de fato temos diariamente experiências que não se refletem em cognição. No entanto, muitas delas podem se refletir em cognição se nossa percepção estiver aberta ou focada nas relações nelas contidas (SCHREGA, 2005, p. 2).

Tais relações no trabalho profissional do arquiteto, segundo Valente (2004), se dividem em duas etapas. Uma delas limita-se ao conhecimento do outro como ser individualizado, único e singular; a outra, refere-se à possibilidade de uma melhora da qualidade de vida da população por meio do trabalho urbanístico.

\begin{abstract}
A significação e o conteúdo no trabalho profissional do arquiteto estão ligados a dois fatores importantíssimos na elevação da qualidade de vida da sociedade. O primeiro diz respeito à criatividade e ao respeito ao reconhecimento do outro como sujeito, que pela sua subjetividade, sempre será diverso dos outros sujeitos, exigindo do profissional da arquitetura um tratamento singular. O segundo diz respeito ao papel social do arquiteto urbanista, cuja profissão, estereotipada como profissão de elite, tem se distanciado de projetos que, através do agenciamento do habitat de nossa extensa população, poderiam realmente contribuir para a elevação da qualidade de vida das pessoas (VALENTE, 2004, p.3).
\end{abstract}

Dessa forma, essas significações e esses conteúdos, importantes para o exercício da profissão de arquiteto, são um limite para aqueles que saem das escolas de Arquitetura sem vivenciar, durante sua formação, experiências de relacionamento com realidades distintas. Estão sujeitos a reproduzirem a imagem profissional estereotipada do arquiteto, a desenvolver uma visão simplificada e simplificadora de suas possibilidades de atuação. Por outro lado, há aqueles que mesmo tendo desenvolvido uma visão abrangente e crítica do universo profissional da arquitetura se frustram por não se verem com capacidade de resolver as distintas demandas provenientes da sociedade. O distanciamento entre educação/escola e o contexto social na formação de arquitetos tem, portanto, sérias implicações. Conforme Arcipreste (2012, p. 20):

Decorrente deste quadro percebe-se a saturação do mercado profissional nas formas convencionais com que o fazer arquitetônico se coloca no imaginário social. Acentuam-se cada vez mais as distâncias entre projeto e obra, entre as práticas mais extensivas e valorizadas do ofício e as reais necessidades 
das cidades, das sociedades brasileiras. Observam-se perdas progressivas de importância do papel do arquiteto na cadeia produtiva com o esvaziamento de seu domínio técnico-construtivo, em meio às alargadas possibilidades tectônicas, cada vez mais articuladas à economia de escala e aos conceitos de adequação ambiental.

\section{Desencontros entre o que os estudantes estudam e as necessidades sociais}

O debate sobre conhecimentos que o arquiteto precisa ter para bem atender às necessidades sociais inclui: os de caráter geral, para lhe dar uma visão ampla sobre como intervir na realidade; os específicos, para possibilitar o enfrentamento da complexidade crescente do trabalho; os necessários à intervenção no projeto arquitetônico e no espaço urbano com perspectiva inovadora e sustentável; os indispensáveis à elaboração de análises de dinâmicas urbanas e de transformações e melhorias dos espaços e, por fim, os relacionados à demanda por projetos arquitetônicos e ambientação de interiores. Todos esses conhecimentos precisam levar em conta, segundo Pavesi (2007, p. 50),

O avanço tecnológico, a transformação acelerada do mundo e a diversificação das demandas sociais [que] vêm provocando a revisão constante de referências e modelos (com a consequente instabilidade dos programas de estudo), que tendem a se escorar no instrumentalismo estreito e no discurso da adaptação e da utilidade momentânea.

Para realizar o encontro entre o que os estudantes estudam e as necessidades sociais, outras questões além das de conteúdo curricular são lembradas pelos autores investigados: a disponibilização de outros espaços físicos acadêmicos que não sejam salas de aula, a diversificação das atividades de ensino-aprendizagem, a iniciação à pesquisa científica e as intervenções de extensão universitária. Com isso se tem uma ampliação do conceito de currículo para dar conta de uma série de experiências, atividades e situações de ensino-aprendizagem, articulando harmoniosamente dimensões da formação científica, técnica, político-social, ética e estética. Mas, para Naruto (2006, p. 92), esses elementos do currículo de formação de arquitetos têm se deteriorado:

Pode-se dizer que esse processo de degradação tenha se iniciado no momento mesmo de sua implantação, quando a atividade de projetação, para a qual foi concebida, sofreu uma divisão artificial e foi distribuída pelas quatro 'linhas de tarefas ou estudos' (PRADO, p. 9), mais tarde caracterizadas como 'áreas' do departamento de 'projeto', ou grupos de dis- 
ciplinas, que compartilhavam a organização dos trabalhos do Departamento de Projeto mas, de fato, mantinham e funcionavam com conteúdos específicos.

Outros aspectos considerados são a estruturação da carga horária dos cursos e a transferência das disciplinas de caráter específico para o fim da formação, fazendo com que os alunos não cheguem a se introduzir em conteúdos referentes à aplicação prática e à discussão das necessidades sociais. Naruto (2006) se refere ainda à inclusão nos currículos de conteúdos pretensamente mais atrativos ou atualizados mas pouco aderentes ao universo arquitetônico e aos problemas reais que o arquiteto precisa responder:

Para os alunos, essa sensação era reforçada pela ausência de um critério maior na composição de seus conteúdos semestrais, seja por força de aprovações ou reprovações processadas isoladamente, seja pela dificuldade em exercer a opção preconizada naquelas disciplinas que, formalmente, deveriam ser de livre escolha: as optativas (NARUTO, 2006, p. 93).

Além disso, houve menções à importância da abordagem multi e interdisciplinar dos conteúdos desenvolvidos, relacionando-os com as condições socioculturais locais, ambientais e econômicas. Ao comentar a necessidade da revisão curricular do curso de Arquitetura e Urbanismo, Pavesi (2007, p. 17) destaca que é "para garantir a abordagem multidisciplinar de temas relacionados a ambiente e desenvolvimento, e seus aspectos e relações socioculturais e demográficos" e para dar "o devido respeito às necessidades definidas pelas comunidades e aos diversos sistemas de conhecimento, que incluem a ciência e as sensibilidades culturais e sociais", mas que, para tanto, seria preciso produzir "materiais educacionais de todos os tipos e para todas as audiências".

A pesquisa realizada encontrou, também, menções à necessidade do desenvolvimento de habilidades peculiares ao arquiteto urbanista e de orientar o aluno a perceber suas dificuldades e a participar do seu processo de formação. Para Schrega (2005, p. 16),

É importante compreender, então, a percepção, não como uma faculdade completamente pronta em todos os indivíduos. Apesar de compartilharmos percepções visuais, sonoras, de olfato, tácteis e outras, vemos a nítida diferença do modo de cada um perceber e utilizar estas informações advindas desta percepção. Quando estamos com um músico, a percepção desenvolvida possibilita que ele indique qualquer nota dissonante em uma música; da mesma forma, um enólogo irá, somente pela fragrância de um vinho, nos dizer, com precisão, o tipo de uva ou característica deste vinho. Em que pese que algumas pessoas estão naturalmente mais dotadas que outras para determinadas percepções, podemos, com um esforço pessoal e alguma orientação e experimentação, desenvolver percepções que nos trazem informações que já recebíamos, mas não processávamos na forma de conhecimento. 
Esse processamento requer que o arquiteto urbanista recorra a conhecimentos históricos, culturais, estéticos, ecológicos, tecnológicos, ambientais, sociológicos, dentre outros, para refletir sobre as relações das pessoas com as construções e o seu entorno, a preservação do meio ambiente e do patrimônio histórico-cultural, as articulações com a sociedade e como elaborar e gerenciar projetos considerando as implicações das mudanças sociais e tecnológicas.

Há, ainda, que considerar a bagagem de conhecimentos, as características pessoais e as vivências e experiências dos alunos, como fazer para que se apropriem dos conhecimentos existentes e incentivá-los a buscar respostas para questões novas, ' considerando o atravessamento dos acontecimentos, as exigências de adaptação, a transformação dos valores e a geração de novas expectativas.

Sintonizar o aluno com os contextos sociais e suas necessidades requer da escola oferecer-lhes conhecimentos e vivências de situações reais e oportunidades para compreender que nem sempre o profissional atua em projetos grandiosos ou decide o traçado urbanístico de grandes capitais, mas pode estar a serviço da população à espera de intervenções que the propiciem uma melhor qualidade de vida.

Essa consideração remete aos dilemas e condições de trabaIho da maioria dos arquitetos contemporâneos. Analisando o exercício da profissão no caso brasileiro, Francisco Segnini Júnior (2002) afirma que a ação do arquiteto se apresenta frequentemente marcada pela noção de métier e sua antítese, a noção de mercado. Esse antagonismo expõe os conflitos entre as formas de caracterização do ofício no imaginário social, marcadas por dimensões artísticas e as reais demandas colocadas pelo mercado de trabalho, nas quais se sobressaem dimensões comerciais e utilitaristas. No mercado de trabalho as dimensões artísticas não deixam de ser consideradas, mas são pautadas por códigos que muitas vezes se distanciam daqueles hegemônicos do campo (ARCIPRESTE, 2012, p.110).

\section{Dificuldades em ampliar a escola para além de seus muros}

A pesquisa realizada mostrou que há novas questões que tornam esse desafio maior, especialmente quando a desconstrução e reconstrução do conhecimento já construído são reclamadas pelas necessidades sociais contemporâneas e, como lembra Lima Neto (2007), os espaços institucionais que intervêm no processo educativo não se restringem ao escolar.

Hoje, com a disseminação das tecnologias digitais de informação e comunicação, ficou mais evidente que a universidade não é o lugar exclusivo 
da produção e socialização de conhecimento. Cabe ao professor introduzir e orientar o aluno nesse novo contexto de informações, estimulando-o a, com censo crítico e iniciativa, ampliar seus horizontes de referências para o exercício profissional. Assim, o trabalho do professor é, sobretudo, o de promover a autonomia e a participação dos alunos, de forma reflexiva e crítica, no relacionamento com saberes extramuros escolares.

A pedagogia capaz de sustentar tal processo de interação com o exterior da escola precisa levar em conta diferenças conceituais e culturais existentes não apenas na comunidade de alunos e professores, mas as pertinentes aos setores com os quais dialogam. O problema é que, segundo Valente (2004), a universidade vem priorizando o ensino em detrimento do aprendizado. Para esse autor,

Estudar, neste modelo de ensino, limita-se à leitura de material previamente selecionado pelo professor, a fim de possibilitar a respondência de questões propostas em prova. Esse tipo de estudo, orientado para a simples repetição cultural, reproduz ideias, mas não força a criação de uma nova produção, pois o exercício da crítica não existe. Já a palavra "aprender" pode ser apresentada como o contrário de ensinar, pois não depende da vontade de outros, mas trata-se de um ato soberano de vontade individual. É preciso querer para poder aprender. Desta forma, no aprender, as atividades estão centradas no aprendiz, como agente principal e responsável pela sua aprendizagem (VALENTE, 2004, p. 32).

Para ir além dos muros da universidade, o aluno precisa desenvolver a capacidade de pensar, raciocinar, refletir, analisar, criticar, questionar, argumentar, trabalhar em equipe, consultar fontes de pesquisa, dialogar com profissionais de outras áreas, se expressar etc. Precisa saber encontrar soluções para problemas da profissão, o que significa ter conduta ética na condução da atividade profissional, ou seja, ter responsabilidade social como arquiteto e urbanista.

[...] esta universidade que transmite apenas saberes prontos, acabados, já se tornou obsoleta. No entanto, sabemos que ela ainda perdura, e faz contribuir para que muitos jovens se deixem levar pelo sistema, inconscientes da profunda significação e responsabilidade que têm perante a sociedade. Há de se convir, no entanto, que estes jovens, e até mesmo a sociedade donde emergem, não podem carregar a culpa pelos conceitos preestabelecidos que trazem. Nasceram e vivem em um mundo onde estes conceitos criaram e criam sistemas de pensamento e ação nos quais se enquadram (VALENTE, 2004, p. 31).

A pesquisa se deparou com a menções a problemas que dificultam à universidade se ampliar para além de seus muros mediante ações e processos por meio dos quais os alunos de Arquitetura e Urbanismo possam testar e so- 
cializar os conhecimentos e procedimentos que lhe são ensinados, colocando-se abertos às observações críticas da sociedade sobre suas intervenções.

Funções significativas do profissional da Arquitetura e Urbanismo são conceber e organizar esteticamente e de maneira funcional o espaço edificado, satisfazendo dentro dos limites da lei e dos valores éticos os interesses daqueles que necessitam desse trabalho. Contudo, há os chamados "erros de projeto", que são aqueles não referidos a falhas de estrutura ou de sistemas, de atribuição direta e exclusiva desse profissional, que podem ter impacto negativo econômico, visual ou de conforto. É importante trazer para o intramuros da escola questões como essa. Não basta tomar conhecimento teórico do Código de Ética Profissional aprovado pela Resolução n. 1.002/02 do Confea (Conselho Federal de Engenharia e Agronomia), que estabelece o princípio ético de eficácia profissional. É preciso levar o estudante a discutir praticamente esse princípio por meio de estudo de casos e observação contextual para que entenda o cumprimento da norma, que prevê o uso de técnicas adequadas, o alcance dos resultados propostos, a qualidade satisfatória nos serviços e produtos e o atendimento às questões da segurança. Um dos autores consultados nesta pesquisa problematiza:

Visões de mundo unitárias, certezas e verdades estabelecidas fundamentaram projetos urbanos genéricos, que desconsideravam as pré-existências e os conflitos da realidade dos grandes centros. Também de edifícios cujos desenhos, pautados por específica gramática formal, reforçavam o valor da arquitetura excepcional, muitas vezes monumental, atrelada ao novo como marca de projetos e obras. Tais concepções ainda fundamentaram uma produção extensiva do mercado que, cada vez mais, foi se desprovendo de qualidade (ARClPRESTE, 2012, p.112).

Ou seja, questões referidas à qualidade social dos projetos, que só podem ser bem avaliadas pelo estudante se ele e seus professores ampliarem a sala de aula para além dos muros da escola, para a vida em sociedade, para as relações sociais. A não correspondência por parte dos arquitetos a essa qualidade social tem muito a ver com a falta de comunicação, respeito e conhecimento da realidade vivida pelos que o procuram para realizar algum trabalho. Bastos (2007, p. 22) fala da "retirada das pessoas dos processos de decisão", da introdução do especialista, com seu próprio sistema de valores, entre o usuário e o edifício, resultando na lacuna entre o mundo construído e aquele desejado e necessário.

Conforme se lê nos trabalhos consultados, o arquiteto precisa aprender a se comunicar, pois o diálogo será parte integrante de sua atividade profissional e isso se torna difícil se o estudante se mantiver limitado apenas ao ambiente da escola e da sala de aula. 
Infelizmente, os acadêmicos de arquitetura em sua maioria não têm o entendimento com a devida clareza da ideia do pensamento arquitetônico, de como a má qualidade dos espaços construídos, sejam eles abertos ou fechados, contribui para a deterioração da qualidade de vida das pessoas. A fragmentação do ensino e o direcionamento deste para o atendimento do mercado provocaram uma sensível diminuição dos estudos das ciências do homem, da filosofia, da história, do humanismo, enfim, até mesmo do saber clássico. Seguramente estes elementos têm contribuído significativamente para chegarmos aonde chegamos (VALENTE, 2004, p.45).

\section{Extensão universitária como prática pedagógica}

A história da "extensão universitária" no Brasil pode ser dividida em três grandes conceitos. No primeiro deles, conhecido como "processo voluntarista e assistencialista", cursos, palestras e eventos são, de forma passiva, levados para a comunidade. A extensão é verticalizada, oferecendo, em forma de mão única, aquilo que tinha em seu domínio.

Por volta de 1912, inicia-se, de forma tímida e recatada, em São Paulo, a extensão universitária dotada de características europeias, onde se enfatizava a educação assistencialista voltada para as classes populares e a prestação de serviços na área rural (NOGUEIRA, 2005, p. 16-17).

Em um cenário social conturbado de lutas, as manifestações estudantis caminhavam em paralelo, concretizando efetivo ganho, por exemplo, a criação do Centro Popular de Cultura (CPC) da União Nacional dos Estudantes (UNE) em 1961. Foi divulgada para a população de baixa renda, por meio das artes (teatro, literatura, música e cinema), a perspectiva de uma nova sociedade.

Outro fator de grande importância de conscientização das massas foi a Campanha de Defesa da Escola Pública, que teve como representantes o Ministério da Educação (MEC), a igreja representada pela Conferência Nacional dos Bispos do Brasil (CNBB), o Centro Popular de Cultura (CPC) e as universidades.

O segundo conceito se define com base em Paulo Freire, cuja proposta pedagógica passa a orientar as práticas da "extensão", discutindo o conceito da troca e a indissociabilidade entre o conhecimento acadêmico e o popular. Paulo Freire foi quem consolidou a relação entre universidade, extensão e as grandes necessidades nacionais, dando um maior significado à luta dos estudantes pela Reforma Universitária. Ele não só desenvolve técnicas de 
aproximação com setores populares como também cria um diálogo entre o saber técnico e o saber da população.

Conhecer, na dimensão humana, que aqui nos interessa, qualquer que seja o nível em que se dê, não é o ato através do qual um sujeito, transformado em objeto, recebe dócil e passivamente, os conteúdos que outro lhe dá ou impõe. [...] O conhecimento, pelo contrário, exige uma presença curiosa do sujeito em face do mundo. Requer uma ação transformadora sobre a realidade. Demonstra uma busca constante. Implica em invenção e em reinvenção. Reclama a reflexão crítica de cada um sobre o ato mesmo de conhecer, pelo qual se reconhece conhecendo e, ao reconhecer-se assim, percebe o "como" de seu conhecer e os condicionamentos a qual está submetido seu ato. [...] Conhecer é tarefa de sujeitos, não de objetos. E é como sujeito e somente enquanto sujeito, que o homem pode realmente conhecer (FREIRE, 2010, p. 27).

O terceiro conceito, definido por "educativo, cultural e científico", considera a universidade e a comunidade agentes ativos do conhecimento e o trabalho é feito de forma continuada e permanente.

Essa visão de extensão que se tem hoje em dia se deu em vasta escala com a criação do Fórum de Pró-Reitores de Extensão das Instituições de Educação Superior Brasileiras (Forproex), em 1987, que em sua primeira reunião define a extensão da seguinte maneira:

A extensão universitária é o processo educativo, cultural e científico que articula o ensino e a pesquisa de forma indissociável e viabiliza a relação transformadora entre a universidade e a sociedade.

A extensão é uma via de mão-dupla, com trânsito assegurado à comunidade acadêmica, que encontrará, na sociedade, a oportunidade da elaboração da práxis de um conhecimento acadêmico. No retorno à universidade, docentes e discentes trarão um aprendizado que, submetido à reflexão teórica, será acrescido àquele conhecimento. Este fluxo, que estabelece a troca de saberes sistematizados/acadêmico e popular, terá como consequência: a produção de conhecimento resultante do confronto com a realidade brasileira e regional; e a democratização do conhecimento acadêmico e a participação efetiva da comunidade na atuação da universidade.

Além de instrumentalizadora deste processo dialético de teoria/prática, a extensão é um trabalho interdisciplinar que favorece a visão integrada do social (ENCONTRO NACIONAL DO FORPROEX, 1987, p. 1).

Em conformidade com as diretrizes do Forproex, a Constituição de 1988 decreta a "indissociabilidade entre ensino, pesquisa e extensão" (BRASIL, 1988, art. 207) e estabelece que "as atividades universitárias de pesquisa 
e extensão poderão receber apoio financeiro do poder público" (BRASIL, 1988, art. 213, § 2 o).

Em 1996, com a criação da Lei de Diretrizes e Bases da Educação Nacional, a extensão universitária não consegue avançar em seu desenvolvimento conceitual. Ela continua negligenciada à função de apenas divulgar suas produções técnicas e acadêmicas à população. Dessa forma, retoma ao primeiro estágio de seu desenvolvimento, o de mão única, tornando a comunidade passiva.

Por outro lado, novas iniciativas, como o Plano Nacional de Extensão, criado em 1998, dão novas perspectivas. O Plano determina o seguinte:

1) a possibilidade de dar unidade nacional aos programas temáticos que já se desenvolvem em diferentes universidades brasileiras; 2) a garantia de recursos financeiros destinados à execução de Políticas Públicas correlatas [...]; 3) o reconhecimento, pelo Poder Público, de que a Extensão Universitária não se coloca apenas como uma atividade acadêmica, mas como uma concepção de Universidade Cidadã; 4) a viabilidade de interferir na solução dos grandes problemas sociais existentes no País (ENCONTRO NACIONAL DO FORPROEX, 2012, p. 8-9).

Avançando no sentido de institucionalizar a extensão, o Plano Nacional de Educação aprova, em 2001, a meta 23, que estabelece:

[...] a responsabilidade das Universidades nas suas funções de Ensino, Pesquisa e Extensão, na formação inicial e continuada dos profissionais da educação básica, e institui que 'no mínimo, $10 \%$ do total de créditos exigidos para a graduação no ensino superior no País será reservado para a atuação dos estudantes em ações extensionistas' (ENCONTRO NACIONAL DO FORPROEX, 2012, p. 9).

Dessa forma, a história da extensão universitária se mostra mais enriquecida e densa por volta do ano 2000, se comparado ao seu início, quando sua maior representatividade girava em torno de ações voluntaristas e assistencialistas. A extensão universitária carrega a responsabilidade de dialogar com a sociedade, respondendo de forma crítica, democrática e produtiva.

Embora não seja obrigatório nesses cursos, o estágio supervisionado foi relacionado pelos autores analisados como estratégia fundamental nesse sentido. Lima Neto (2007, p. 52) informa que entre seus pesquisados há os que reconhecem "haver aí uma falha na legislação, considerando o fato um retrocesso no ensino e na formação em relação aos países desenvolvidos". Pondera que é preciso que ele seja supervisionado por professores para que possa permitir ao aluno um desenvolvimento global, ter amparo teórico e prático. 
Schrega $(2005$, p. 6) se refere a duas outras estratégias:

O aprendizado baseado em problema (Problem Based Learning) ou aprendizado baseado em produto (Product Based Learning) são alguns dos muitos caminhos no ensino da arquitetura que procuram sensibilizar, despertar a percepção, abrir as portas do conhecimento contido ao redor, ao alcance dos olhos de cada um de nós.

Trata-se de uma metodologia que busca estimular a atitude ativa do aluno em busca do conhecimento. O ponto de partida é a proposta de resolução de um problema concreto. Ela engloba a apresentação e identificação desse problema, a formulação de hipóteses explicativas, a identificação dos conhecimentos que os alunos precisam buscar, estudo individual e a discussão coletiva sobre os resultados da pesquisa realizada e as possíveis respostas para o problema. A adoção dessa proposta pelos cursos de Arquitetura e Urbanismo tem implicações para organização curricular, papéis docentes, criação de uma comissão especial para a seleção dos problemas, levantamento de problemas suficientes e adequados para o cumprimento do currículo, reorganização da sala de aula e mutualidade entre estudos individuais e grupais. Pressupõe interações e uma atitude ativa do aluno.

A extensão na faculdade Pitágoras está descrita no Plano de Desenvolvimento Institucional (PDI), da seguinte maneira:

A extensão universitária, como prática acadêmica, é instrumento de articulação com os diversos segmentos sociais, de forma programada e sistemática, envolvendo um processo orgânico que não se confunde com assistencialismo. É fator integrador do ensino e da pesquisa objetivando responder à demanda social e representa um compromisso da instituição com a comunidade, visando implementar projetos, enquanto situa a extensão na linha pedagógica na qual os docentes desenvolvem ações que contribuam para as transformações sociais, econômicas e políticas, procurando instituir os valores da democracia e dos direitos humanos (FACULDADES INTEGRADAS PITÁGORAS, 2015, p. 41).

O Escritório Modelo da Faculdade Pitágoras, unidade de Belo Horizonte, recém-inaugurado, foi idealizado sob as normas do Projeto de Orientação a Escritórios Modelo de Arquitetura e Urbanismo (Poema) e tem como objetivo orientar e caracterizar os Escritórios Modelo de Arquitetura e Urbanismo (Emaus), indicando rumos em sua formação, funcionamento e manutenção.

Esse projeto está dividido em duas partes: a primeira delas apresenta a visão dos estudantes de Arquitetura sobre a extensão universitária e define, de modo geral, um escritório modelo de Arquitetura e Urbanismo.

A segunda parte é composta da Carta de Princípios dos Escritórios Modelo de Arquitetura e Urbanismo, desenvolvido no IV Seminário Nacional so- 
bre Escritórios Modelo de Arquitetura e Urbanismo (Senemau), São Paulo, 01/2000 e posterior revisão iniciada a partir do V Senemau, Campo Grande, 01/2001, que traz as normas e diretrizes para montagem de um escritório nessa área.

A realidade dessa inovação é um grupo expressivo em participação. Nesta atuação que dialoga com a sociedade civil de baixa renda, além de estar propondo soluções técnicas para as áreas escolhidas pela população, os alunos estão vivenciando situações de convívio e aprendizado, ainda não presenciados por eles dentro do universo acadêmico.

\section{Recursos pedagógicos no ensino da Arquitetura e Urbanismo}

A relação professor/aluno aparece nas análises das obras pesquisadas como um recurso importante para a formação de arquitetos. Fala-se do papel do docente de orientar os alunos na produção dos conhecimentos em face de situações-problema e de levar em conta as particularidades, singularidades e desafios de cada aluno.

também lançar

mão do recurso

da pesquisa para

que a prática pedagógica se

aproxime do contexto do mundo real

Pavesi (2007) lembra que o Parecer n. 112/2005, de 6 de abril de 2005, da Câmara de Educação Superior do Conselho Nacional de Educação, aprovou as Diretrizes Curriculares Nacionais do curso de graduação em Arquitetura e Urbanismo, considerando a necessidade de assegurar a formação de profissionais generalistas. Ou seja, o curso precisa tornar cada aluno apto ao exercício de um leque de funções muito amplo, de caráter genérico.

A autora também se refere à dificuldade de se elaborar projetos pedagógicos que consigam aliar pedagogia e conteúdos próprios das realidades sociais e culturais singulares e das experiências particulares de cada aluno ou grupo de alunos.

Já nos Emaus, a escolha de "Projetos" é feita de forma a ter um melhor aproveitamento acadêmico, por isso é importante que os próprios estudantes busquem um projeto que lhes proporcione acúmulo de conhecimentos e experiências como cidadãos e futuros profissionais. Normalmente, o tempo de estudos e projetos dentro do Emau é diferenciado de projetos acadêmicos hipotéticos, ou de projetos comerciais. O contato direto com a comunidade, o processo projetual participativo, o enriquecimento do projeto com consultas e apoio de outras áreas do conhecimento, são fatores que qualificam muito esses projetos, mas também fazem aumentar seu tempo. Em escritórios de arquitetura privados ou entidades com fins lucrativos seria inviável a captação de projetos com a demanda de tempo absorvida pelo 
Emau, não de uma maneira desgastante, mas de uma maneira didático-pedagógica.

Isso significa que o professor deve também lançar mão do recurso da pesquisa para que a prática pedagógica se aproxime do contexto do mundo real, para levar o aluno a ser sujeito observador e aprender enquanto produz seu projeto.

Recursos teóricos são necessários para pavimentar o caminho a seguir pelo estudante, que deve elaborar um mapa que represente sua posição atual e o local onde pretende chegar, sob supervisão minuciosa. O aluno precisa contar, então, com recursos de teorias, ferramentas e métodos, tendo em mira seu processo pessoal de construção de conhecimentos. Nesse processo, o aluno, segundo Carsalade (1997, p.56), "conta com seus próprios conceitos anteriormente estabelecidos a partir dos quais constrói os novos, conta com seus conhecimentos procedimentais, com seu esforço pessoal para aprender, com sua motivação".

O aluno precisa, assim, construir significados sobre os conteúdos que aprende, representações sobre sua própria situação como aprendente e estabelecer estratégias de aprendizado que reforcem sua autoconfiança, o ajudem a produzir uma imagem positiva de si mesmo em relação ao que pretende alcançar. Para Carsalade (1997, p.55), esse processo de se educar "é o motor para o desenvolvimento pessoal globalmente entendido, o que supõe incluir também as capacidades de equilíbrio pessoal, de inserção social e de relação interpessoal".

Carsalade faz uma referência a Walter Gropius, diretor do Curso de Arquitetura da Universidade de Harvard, fundador da escola Bauhaus, marco no design, arquitetura e arte moderna, portanto, um dos principais nomes da arquitetura do século 20:

A diferença que Gropius estabelece a todo o momento entre método de ensino e instrução, o leva a reafirmar o contato com a realidade como importante técnica pedagógica. Tal contato com a realidade far-se-ia através do entendimento de demandas reais e da realidade de cada material. Assim "Nossa ambição consistia em arrancar o artista criador de seu distanciamento do mundo e restabelecer sua relação com o mundo real do trabalho, assim como relaxar e humanizar ao mesmo tempo a atitude rígida, quase exclusivamente material do homem de negócios" (GROPIUS, 1972, p. 32 apud Carsalade, 1997, p.104).

Donde se conclui que o contato com a realidade é, em si, um importante recurso pedagógico, mas precisa passar pela relação dialética entre o entendimento crítico das demandas que dela advém e a relação de cada aluno com esse mundo real da atividade de trabalho. 
O recurso ao exercício da comunicação adequada também seria fundamental. Ou seja, a importância do cuidado com o uso das palavras, das linguagens. O recurso do diálogo permanente, a começar pelo que se estabelece entre orientando e orientado (LIMA NETO, 2007).

\section{Aplicação do princípio educativo do trabalho no ensino da Arquitetura e Urbanismo}

Esse princípio diz respeito ao processo prático e concreto mediante o qual o ser humano modifica a si mesmo ao atuar sobre o mundo exterior e modificá-lo. Na arquitetura, diz respeito à atuação sobre elementos ou objetos de uma construção ou ambiente, tais como a cidade, a casa, a parede, que, por sua vez, destinam-se a abrigar ou possibilitar diferentes tipos de atividades humanas. Por outro lado, a arquitetura se refere ao produto dessa atividade, ao conjunto de obras humanas.

Lembra Vidigal (2010) que o arquiteto utiliza sua capacidade de imaginação recorrendo às práticas sociais que o auxiliam na escolha do caminho a ser seguido para encontrar a solução de um determinado problema.

[...] além da importância do trabalho conjunto para alcançar resultados, o fato de que não desenhar a partir do nada significa ter de buscar informações, referências, bases teóricas, ou seja, fundamentar o projeto em algo que tenha sentido e consistência (VIDIGAL, 2010, p. 32).

Dessa forma, o que não faria sentido é a ideia de que a atividade advém da intuição pura e simples, do querer por querer, sem reflexão ou justificativa, pois os caminhos percorridos pelo projeto de arquitetura estão carregados de historicidade, de decisões éticas, de sequências lógicas, políticas, de significados sociais e sentidos pessoais. Não se trata, portanto, de visualizar um problema e, de pronto, propor a solução que primariamente surgir no horizonte, mas de estabelecer um caminho que contemple o atendimento das necessidades sociais envolvidas na situação, considerando também os conflitos implicados e os que, possivelmente, poderão surgir ao longo do percurso e futuramente.

Essa consciência, discutida em sala de aula, é fundamental e pode transformar a metodologia de trabalho do professor. Ao compreender os princípios básicos da arquitetura e a atividade de fazer arquitetura, o aluno pode refletir sobre as questões nela envolvidas e ver que os dilemas enfrentados no momento de criação de um projeto em relação à forma de como pensar, 
como sintetizar, como fazer ou como construir estão além do processo individual de projeto.

É importante que se rompa com a percepção de que as práticas trabalhadas na instituição escolar estejam desligadas das exercidas no mundo real. O estudante precisa saber que os questionamentos e os caminhos desenvolvidos em sala de aula o acompanharão ao longo de sua jornada profissional. Para isso, é importante que o processo pedagógico trabalhe situações-problema reais. Mais do que isso, precisa colocar em discussão o aprofundamento técnico e a pertinência ética, política e econômica das soluções encontradas.

Dessa forma, a atividade do aluno, além de orientar a forma como se apresenta o pensamento no momento da concepção de um projeto, se torna importante para a sua formação como arquiteto, como sujeito crítico e profundamente conectado com o que a sociedade espera dele.

O arquiteto, ao desenvolver sua atividade, passa por diversas informações acerca do que se pretende resolver. Nessa busca é importante exercitar sua capacidade de interação com outros profissionais relacionados direta ou indiretamente ao projeto. Sendo assim, é importante que, ainda como aluno, tenha possibilidades de desenvolver diálogos, especialmente em atividades realizadas em grupo.

O trabalho do arquiteto é coletivo. O que ele pensa ou projeta é para alguém, o que requer visão multilateral. Ele traz sua bagagem informativa, os conhecimentos considerados necessários, mas não pode impor suas apreciações pessoais. Conforme Valente (2004, p.149), "o trabalho em equipe também é importante, pois força a interação entre os componentes do processo, fazendo com que haja troca de conhecimento, sentimentos e emoções."

A realidade da atividade do arquiteto, ao se transportar para o ambiente escolar, determina a necessidade de dinâmicas que promovam a interação entre os alunos, fazendo com que haja um contínuo processo de aprendizagem no coletivo. Dessa forma, atividades em grupo devem ser propostas pelos professores, de maneira que o aluno possa desenvolver sua capacidade de interação.

Nesse sentido, é importante que os alunos sejam motivados a realizar trabaIhos em equipe, que lhes permitam trabalhar como indivíduos socialmente contextualizados. Esse processo os ajudará a pensar os problemas sob diferentes ângulos e criticamente.

O trabalho em grupo é também uma importante ferramenta para preparar individualmente o aluno para a atividade da arquitetura, que requer a capacidade de argumentação e de construção de consensos entre os envolvidos 
no projeto. Valente (2004) ressalta que o trabalho em grupo ajuda a ampliar as capacidades dos alunos para trabalhar solidariamente e com ética política, mas que é importante considerar a importância do trabalho individual e de como ele se compõe na atividade coletiva.

\begin{abstract}
No entanto, o trabalho em equipe, sobretudo nos grupos com grande número de elementos, facilmente degenera em desvio do assunto em pauta. Muitas vezes as atividades são marcadas pela dificuldade de se organizar e de conseguir a colaboração máxima de todos. Na ânsia de ver o trabalho terminado, e por um instinto de qualidade individualizada, alguns componentes do grupo, acabam tomando para si o que deveria ser um esforço comum (VALENTE, 2004, p.149).
\end{abstract}

Valente (2004, p. 149) considera, entretanto, a importância do trabalho individual, "pois força o aluno para a iniciativa pessoal, renovando constantemente o interesse, a produtividade sistemática e cumulativa, a ocupação de espaço próprio", mas sem que isso se transforme em concorrência.

Seja grupal, seja individual, o importante é que o princípio educativo do trabalho seja exercitado na formação dos futuros profissionais em Arquitetura, indicando-Ihes desafios a serem superados ao longo de sua formação e de sua atuação profissional.

\title{
8. Estratégias para fazer a inserção do ensino de Arquitetura e Urbanismo na prática social
}

Pavesi entrevistou professores de Arquitetura e afirma que eles

[...] reconhecem que o equacionamento dos problemas que o Curso enfrenta atualmente requer uma mudança estrutural que contemplaria a atualização de sua pauta, dos conteúdos curriculares, das estruturas didático-pedagógicas, bem como uma articulação melhor entre áreas de ensino e entre ensino, pesquisa e extensão (PAVESI, 2007, p. 104).

A escuta a seus alunos revelou demandas para a necessidade de aproximação do projeto do curso à realidade profissional, melhoria dos conteúdos de tecnologia voltados para a aplicação em projeto e de aulas teóricas sobre projeto, entre outros. Vidigal (2010, p. 80) relata que:

Na opinião de alguns estudantes, os exercícios de projeto no ateliê se distanciam da prática diária do que seria um escritório de projetos de arquitetura. Os estudantes se veem aprendendo algo que não terá utilidade nenhuma no futuro, e o sentimento de frustração com as expectativas de trabalhar com demandas reais acaba se refletindo na falta de estímulos 
pessoais para o envolvimento do aluno no processo de aprendizagem.

A estratégia de vivências em estágios particulares ou no Emau, onde a atividade de extensão é formada e gerida por alunos que, apesar de terem a orientação de professores, possuem uma autonomia de debate, argumentação e criação muito grande, pode possibilitar ao graduando conversar com clientes para entender suas necessidades e pensar em soluções. Há também a possibilidade de realização de simulações de problemas reais no contexto da sala de aula. Comparando essas duas estratégias, nota-se, contudo, diferenças significativas. Em sala de aula, o aluno discutirá as soluções técnicas, sociais e políticas longe dos desconfortos e da pressão por urgência e eficiência que encontra nas atividades de estágio. Essas semelhantes ao que efetivamente irá viver na sua rotina como profissional. No entanto, considera-se que o estágio ofereça ao futuro arquiteto oportunidades para se relacionar com diferentes públicos, especialmente com os socialmente em desvantagem, pois não só construções faraônicas, grandes empreendimentos e mansões constituem o trabalho do profissional da área.

Por fim, a articulação entre ensino, pesquisa e extensão se apresenta como estratégia de aproximação didática com as práticas sociais. Esse diálogo seria essencial para elevar o nível científico e técnico da formação profissional em Arquitetura.

\section{Considerações finais}

Este artigo trouxe contribuições de dissertações e teses de dez autores que pesquisaram a formação de arquitetos com a finalidade de discutir a promoção da formação profissional referenciada socialmente e comprometida com o desenvolvimento local e a história da extensão universitária, mostrando seus vários conceitos em suas diversas épocas. Mostrou, por meio do Poema, projeto da Federação Nacional de Estudantes de Arquitetura e Urbanismo do Brasil (Fenea), desenvolvido no IV e V Senemau, a prática pedagógica desenvolvida na Faculdade Pitágoras.

As categorias que orientaram essa pesquisa bibliográfica foram definidas com o intuito de fornecer elementos para o que se propôs a pesquisar. Contudo, entende-se que os resultados obtidos com essa sistematização podem ser relevantes para outros propósitos relacionados à formação de arquitetos ou à educação profissional de maneira geral.

Para cada uma das sete categorias de análise que orientaram essa pesquisa bibliográfica foram colhidos elementos importantes para a reflexão crítica de educadores comprometidos com a formação de profissionais críticos e comprometidos com a transformação do mundo do trabalho. São questões

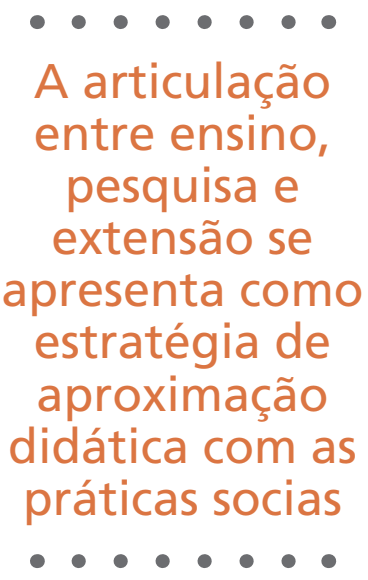

A articulação entre ensino, pesquisa e extensão se apresenta como estratégia de aproximação didática com as práticas socias 
sobre como estreitar as relações da educação/escola e o contexto social e as necessidades sociais; como ampliar a escola para além dos seus muros; como explorar práticas e recursos pedagógicos e aplicar o princípio educativo do trabalho no ensino-aprendizagem e como fazer sua inserção na prática social. Espera-se, também, que este artigo incentive o aprofundamento das pesquisas sobre a concretização desses desafios.

\section{Referências}

ARCIPRESTE, C. M. Entre o discurso e o fazer arquitetônico: reflexões sobre 0 ensino de arquitetura e urbanismo e seus referenciais a partir do trabalho final de graduação. 2012. Tese (Doutorado em Arquitetura e Urbanismo) - Faculdade de Arquitetura e Urbanismo, Universidade de São Paulo, São Paulo, 2012.

BASTOS, C. M. V. A participação do usuário no processo de projeto de habitação de interesse social em sistemas autogestionários. 2007. Dissertação (Mestrado em Arquitetura) - Escola de Arquitetura, Universidade Federal de Minas Gerais, Belo Horizonte, 2007.

BRASIL. Constituição (1988). Constituição [da] República Federativa do Brasil. Brasília, DF: Senado Federal, 1988.

BRASIL. Lei no 12.378, de 31 de dezembro de 2010. Diário Oficial da União, Brasilia, DF, 31 dez. 2010. Edição extra. Disponível em: <http://www.planalto.gov.br/ ccivil_03/_ato2007-2010/2010/lei/L12378.htm>. Acesso em: 3 abr. 2016.

CAMPOS, R. Experiência de trabalho: experiência profissional. In: FIDALGO, F; MACHADO, L. (Ed.). Dicionário da educação profissional. Belo Horizonte: UFMG/ Núcleo de Estudos sobre Trabalho e Educação, 2000. p. 153.

CARSALADE, F. L. Ensino de projeto de arquitetura: uma visão construtivista. 1997. Dissertação (Mestrado em Arquitetura) - Escola de Arquitetura, Universidade Federal de Minas Gerais, 1997.

ENCONTRO NACIONAL DO FORPROEX, 1., 1987, Brasília. Conceito de extensão, institucionalização e financiamento. Brasília, DF: Fórum de Pró-Reitores de Extensão das Universidades Públicas Brasileiras: UnB, 1987. Disponível em: <http:// www.renex.org.br/documentos/Encontro-Nacional/1987-I-Encontro-NacionaldoFORPROEX.pdf>. Acesso em: 10 mar. 2017.

ENCONTRO NACIONAL DO FORPROEX, 31., 2012, Manaus. Carta de Manaus. Manaus: Fórum de Pró-Reitores de Extensão das Universidades Públicas Brasileiras, maio 2012. Disponível em: <http://www.Politica\%20Nacional\%20de\%20 Extensao\%20Universitaria\%20-FORPROEX-\%202012.pdf>. Acesso em: 1 mar. 2017.

FACULDADES INTEGRADAS PITÁGORAS. PDI Plano de Desenvolvimento Institucional, 2015-2019. [Belo Horizonte, 2015?]. Disponível em: <http://www.fipmoc.edu.br/images/cpa/pdi-2015a2019.pdf>. Acesso em: 17 mar. 2017. 
FEDERAÇÃO NACIONAL DE ESTUDANTES DE ARQUITETURA E URBANISMO DO BRASIL. Poema. [S.I., 2007]. Disponível em: <http://www.fenea.org/poema >. Acesso em: 25 fev. 2017.

FREIRE, Paulo. Extensão ou comunicação? 14. ed. Rio de Janeiro: Paz e Terra, 2010.

LIMA NETO, J. P. 0 ensino de arquitetura como agente transformador da prática profissional. 2007. Dissertação (Mestrado em Arquitetura e Urbanismo) Escola de Arquitetura, Universidade Federal de Minas Gerais, Belo Horizonte, 2007.

NARUTO, M. Repensar a formação do arquiteto. 2006. Tese (Doutorado em Arquitetura e Urbanismo) - Faculdade de Arquitetura e Urbanismo, Universidade de São Paulo, São Paulo, 2006.

NOGUEIRA, Maria das Dores Pimentel. Políticas da extensão universitária brasileira. Belo Horizonte: Ed. UFMG, 2005.

PAVESI, A. A ambientalização da formação do arquiteto: o caso do Curso de Arquitetura e Urbanismo da Escola de Engenharia de São Carlos. 2007. Tese (Doutorado em Educação) - Centro de Educação e Ciências Humanas, Universidade Federal de São Carlos, São Carlos, 2007.

SAVIANI, D. Pedagogia histórico-crítica: primeiras aproximações. 11. ed. rev. Campinas: Autores Associados, 2011.

SCHREGA, A. C. E. Conhecimento tácito e reflexão na ação: em busca de paradigmas emergentes no ensino de arquitetura e urbanismo na Pontifícia Universidade Católica do Paraná. 2005. Dissertação (Mestrado em Educação) Pontifícia Universidade Católica do Paraná, Curitiba, 2005.

PRONSATO, S. A. D. Para quem e com quem: ensino de arquitetura e urbanismo. 2008. Tese (Doutorado em Arquitetura e Urbanismo) - Faculdade de Arquitetura e Urbanismo, Universidade de São Paulo, São Paulo, 2008.

VALENTE, N. Estratégias para uma aprendizagem no ensino de arquitetura. 2004. Dissertação (Mestrado em Educação) - Centro de Teologia e Ciências Humanas, Pontifícia Universidade Católica do Paraná, Curitiba, 2004.

VIDIGAL E. J. Ensino de projeto arquitetônico: um estudo sobre as práticas didáticas no curso de arquitetura e urbanismo da Universidade Federal do Paraná. 2010. Tese (Doutorado em Arquitetura) - Faculdade de Arquitetura e Urbanismo, Universidade de São Paulo, São Paulo, 2010. 

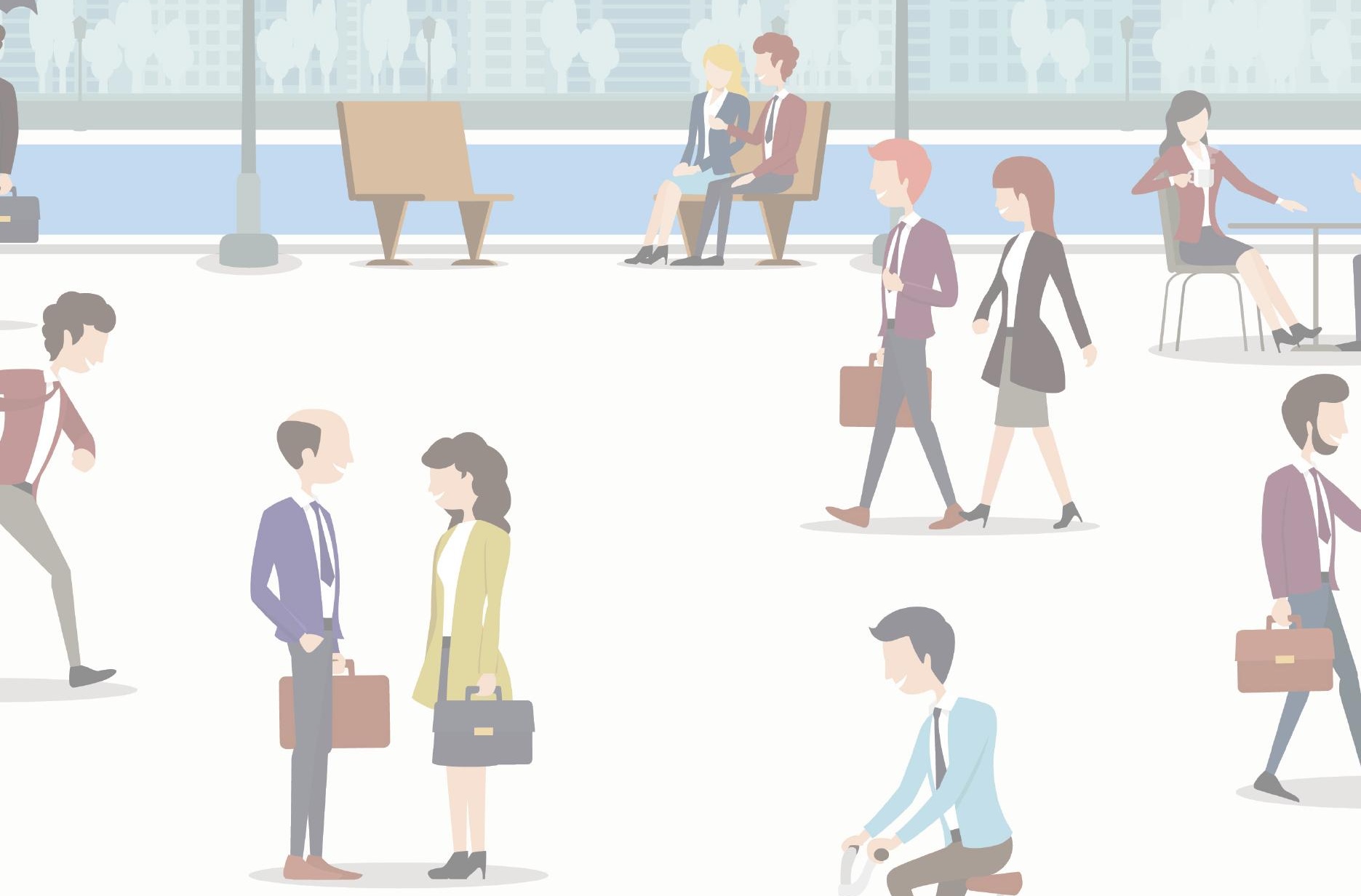

B. Téc. Senac, Rio de Janeiro, v. 43, n. 2, p. 188-211, maio/ago. 2017. 